\title{
Poverty dynamics and vulnerability to poverty: An empirical analysis using general household surveys
}

\author{
Priviledge Cheteni, Yohane Khamfula \& Gisele Mah \\ ${ }^{1}$ School of Economic and Decision Sciences, North-West University, \\ Mafikeng, South Africa \\ Email: pcheteni@icloud.com
}

\begin{abstract}
Background: This study analysed determinants of vulnerability to poverty in South Africa utilising the General Household Surveys from 2012 to 2015.

Data source and methods: The Foster Greere Thorbecke poverty index by groups and income components using the Shapley Value was used to identify household vulnerability status. A multinomial logit model was used to investigate factors that contribute to vulnerability to poverty.

Results: The study findings pointed out that high-income variability contributes to vulnerability and poverty among urban and rural areas.

Additionally, the findings of the study demonstrated that only a few households fall in the middle (lower bound) poverty lines.
\end{abstract}

Conclusions: Race and location are strong predictors of poverty in South Africa.

Keywords: Income distribution, Inequality, Multinomial logit model, Principal Component, sub-Sahara

\section{JEL Classification C2I C6I I32 OI0 R20}

\section{Introduction}

During the past decade, South Africa has faced numerous challenges including unpredictable fuel prices, volatile exchange rate, severe weather events and recently the downgrading of the economy to junk status. However, the lack of longitudinal data has led to neglect in studies focusing on vulnerability and poverty dynamics. Studies conducted by Vakis, R., Rigolini, and Lucchetti (2015) and Ferreira, Messina, Rigolini, López-Calva, Lugo (20/3) focused on intragenerational mobility on the middle class and chronic poor in South Africa and found that the middle class had a low probability of experiencing poverty. The poor are the most vulnerable because of their location and exposure to risky events such as natural disasters, economic disturbances to name a few (Sharma, Burton, van Aalst, Dilley, M \& Acharya, 2000).

Devereux (1999) and Sharma et al, (2000) found that the poor have less access to assets that can be used to manage risk through their responses. Therefore, the poor tend to be disfranchised and their ability to managed risk is compromised (Narayan, Chambers, Shah, \& Petesch, 2000). In support of this view, Winters et al (2004) reiterate that vulnerability is a key element of poverty and a major concern, although the authors admit that the two are not coterminous. Poverty is seen as demonstrating a wellbeing status; yet, vulnerability is 4801 said to be stochastic and dynamic (Winters A., McCulloch, N. and McKay, A., 2004). Pritchett, Suryhadi and Sumarto (2000) define vulnerability as the probability of being below the poverty line in a three-year period. On the other hand, a vulnerability can then be said to be a measure of wellbeing, reflecting the likely future prospects of a household (Chaudhuri, 2003). Broadly, risk can come from covariate shocks or idiosyncratic shocks. Householdspecific shocks can be a death in the family of an income earner, unhygienic living conditions or any unfavourable household situation. Yet, covariate shocks are community-level shocks such as natural disasters like cyclone, floods, drought to name a few. All these have the potential to contribute to volatility in a household income. Therefore, vulnerability is viewed as a product of poverty, which exposes household abilities to cope with risks. As stated by Carter and Barrett (2006), a household can be in persistent poverty due to risks. Thus, an understanding of how households should cope with such risk is an important step in poverty reduction efforts. Ajay and Rana (2005) point out that knowing the characteristics of movements in and out of poverty can help policymakers.

A household vulnerability is said to be in four ways namely; changes in income, changes in household portfolio activities, poverty traps and changes in http://aps.journals.ac.za 
variability of existing income. According to Reardon (1997), a household has a variety of sources of income, as a result, a household maximises a portfolio which increases its utility by taking into account the degree of the risk aversion (Ellis, 1993). Thus, any changes in their portfolio arrangements have a likelihood of increasing their vulnerability to poverty. Similarly, income variability can pose a challenge to struggling households by exposing them to shocks both endogenous and exogenous. For instance, Gilbert and Varangis (2002) claim that abolishment of official purchasing incentives increased cocoa price variance in West Africa. Such changes exposed households to shocks. The study of Jalan and Ravallion (1997), in China, demonstrated that geographical externalities in rural areas in terms of human capital factors and endowment affected household productivity. Jalan and Ravallion (1999) further noted that the poor are not well insured and are less able to deal with shocks compared to the non-poor. This view was reaffirmed by the World Bank's introduction of a social risk management framework.

This study extends on the growing literature strand in quantitative economics by focusing on the ex-ante measures of poverty (Meyer \& NishimweNiyimbariwa, 2016; Golaz \& Rutaremwa, 20II; Zhang \&Wan, 2006; Chaudhuri, Jalan \& Suryahadi, 2002). Mina and Imai (2016) point out that it is very imperative to consider macro and micro shocks in poverty analysis. This is because households are faced with various vulnerabilities most emanating from global shocks. These shocks add-on persistent exposure to micro level shocks in developing countries (Dercon, 2005). Some of those shocks include economic shocks in the form of unemployment, adverse prices and a decline in productivity. On the other hand, weather-related shocks such as droughts, floods, pest and other natural disasters. Rural households usually get more exposure to such shocks, and their inability to deal with them complicates the problem. While some of the shocks are at an individual household level, other affect communities and villages. As a result, it is very critical to assess the extent to which households are exposed to such shocks and how they can mitigate them. From a policy viewpoint; it is important that successful poverty reduction policies should focus on people at risk in their near future. Despite the relevance of this issue, studies on vulnerability and its determinants are limited, especially in the SubSaharan Africa where poverty is high. This is largely caused by the lack of specialised data to analyse vulnerability, as well as methodological challenges in analysing risks.
The remainder of the article is structured as follows: section 2 summarizes vulnerability issues and how they are estimated; it contains a description of the data and methodology used in examining poverty dynamics. Section 3 presents the results and discussions on household characteristics of the vulnerable. Lastly, section 4 concludes the study and provides recommendations.

\section{Methods of the study}

In economics, vulnerability is an outcome of a process of households' responses to risks given a set of underlying conditions (Alwang, Siegel \& Jorgensen, 200I). Consequently, vulnerable households are the ones who are likely to fall into poverty because of cumulative risks and responses.

Vulnerability analysis provides information on how individuals and households can be affected by shocks both exogenous and endogenous. Previous approaches to vulnerability were more of qualitative assessments; however, recently there is an increase in quantitative methods used to measure vulnerability. There are three approaches in vulnerability analysis namely Vulnerability as Expected Poverty (VEP), Vulnerability as Low Expected Utility (VEU) and Vulnerability as Uninsured Exposure to Risk (VER). The main important feature in all these approaches is that they are based on welfare indicators; this can be consumption, expenditure or income. The VEP and VEU approach make reference benchmark to a welfare indicator and the probability of falling below the benchmark. Yet, the VER does not assign any probabilities, instead, it assesses if whether observed shocks generate welfare losses. The expected poverty approach reduces to a basic cumulative distribution of income below the poverty line (probability of poverty) (Christiaensen \& Subbarao, 2009). For simplicity in conceptualising vulnerability analysis, the study focused on the VEP approach. Thus, we outline the following equation, where the poverty index for a household $i$ at the time t.

$$
p_{i t}=\frac{u(z)-u\left(c_{i t}\right)}{|u(z)|} \quad(\text { eq I })
$$

In this case, $\boldsymbol{z}$ is the poverty line, $c_{i t}$ is the household $i$ consumption level at $t$, and $u($.$) is an$ increasing function. We then take the following function as the form for $u($.

$$
u(c)=z^{\alpha}-(\max \{0, z-c\})^{\alpha} \quad(\text { eq } 2)
$$

$\alpha$ take integer values $0, I, 2 \ldots n$ respectively, then the poverty index in eq2 can be reduced to the Foster-Greere-Thorbecke (1984) poverty measures as follows:

$$
p_{\propto, i t}=\left(\max \left\{0, \frac{z-c_{i t}}{z}\right\}\right)^{\propto} \quad(\text { eq3 })
$$

Where $\alpha=0$, the poverty index is a binary indicator, $\alpha=I$ the index estimates the poverty gap 
ratio, and $\alpha=2$ represents the squared poverty gap. Therefore, to estimate vulnerability we have the following function

$$
\begin{aligned}
& v_{\propto . i t}=E\left[P_{\propto, i, t+1}\left(c_{i, t+1}\right) \mid F\left(c_{i, t+1}\right)\right] \text { (eq4) } \\
& =\int\left(\max \left\{0, \frac{z-\left(c_{i, t+1}\right)}{z}\right\}\right)^{\alpha} d F\left(\left(c_{i, t+1}\right)\right) \\
& =F(z) \int_{c}^{z}\left(\frac{z-\left(c_{i, t+1}\right)}{z}\right)^{\alpha} \frac{f\left(c_{i, t+1}\right)}{F(z)} d c_{i, t+1}
\end{aligned}
$$

Where $F\left(c_{i, t+1}\right)$ is the cumulative distribution and, $f\left(c_{i, t+1}\right)$ is the density function. Vulnerability can be defined by the household's ability to smooth consumption in response to income shocks, with those households who cannot deal with the income shocks leading to them being vulnerable. A problem arises when a household's vulnerability is defined in terms of its smoothing consumption ability in face of income shocks. A household may have a high ability to smooth consumption in face of numerous income shocks. Therefore, the expected poverty approach is said to take both components of vulnerability into account. At the same time, vulnerability can also be defined as exposure to adverse shocks in welfare. Nonetheless, whatever approach is chosen, specifying the consumption process is crucial because vulnerability is an ex -ante measure, yet poverty is ex- post measure. Consumption is dependent on the current income and the future expected income, and other household characteristics factors. Some which may be observable or unobserved (socio-economic). The consumption function, hence, takes the following form:

$$
c_{i t}=c\left(X_{i}, \beta_{t}, \alpha_{i}, \varepsilon_{i t}\right)(\text { eq } 5)
$$

Where $X_{i}=$ bundle of observable household characteristics,

$\beta_{i}=$ vector of parameters describing an economy at a certain time $t$

$\alpha_{i}=$ unobserved time-invariant household level effect; and

$\varepsilon_{i t}=$ represents idiosyncratic factors that contribute it differential welfare purposes.

We can rewrite the expression by substituting eq 5 into eq4, we get the following:

$$
\text { (eq6) }
$$$$
\left.v_{i t}=E\left[P_{\propto, i, t+1}\left(c_{i, t+1}\right)\left|F\left(c_{i, t+1}\right)\right| X_{i}, \beta_{t}, \alpha_{i}, \varepsilon_{i t}\right)\right]
$$

As shown in the expression (eq6), a household vulnerability level can be derived from stochastic properties of inter-temporary consumption stream it faced, and these depend on the household characteristic and the environmental characteristics in which it operates. The expression on its own allows interactions between multiple cross-sectional determinates of a household vulnerability level. For instance, $X_{i}$ can include variables such as the household size, farm areas to name a few. However, such an approach when estimating vulnerability requires an estimation of the distribution of 4803 household income (mean or variance), specification of the poverty line and a cut-off point where probabilities can be assigned to identify if the household is vulnerable or not.

\section{Data}

The study makes use of General Household Surveys (GHS) conducted in 2012 and 2015. According to Statistics South Africa (StatsSA), the data collection period for the survey covers a 12-month period, and the samples include domestic households, holiday workers and households' workers in residences. The surveys cover 25330 households in 2012 and 21601 households in 2015. They contain information on household demographics, ethnicity, health, education, economic activities, service delivery, employment, assets and a number of institutional and infrastructural variables. The GHSs are very important because they follow a panel of urban and rural households every year, although, the two samples are representative of the population nationally, we cannot guarantee that it is true reflection of both populations in urban and non-urban areas due to a number of factors, such as inaccessible to certain areas, especially in rural areas. Nonetheless, we are very confident that our results provide useful inferences for the population in South Africa.

\section{Modelling vulnerability and poverty}

To measure households' vulnerability, poverty indicators are used to estimate the probability of households becoming poor (McKay and Lawson, 2003; Jana and Ravallion, 1998). Following StatsSA (20I4), the study used three national poverty profiles to determine vulnerability. Firstly, the food poverty line (FPL) which is the level of consumption below, which individuals are unable to purchase sufficient food to provide them with an adequate diet. The Lower Bound Poverty Line (LBPL) includes non-food items, although it requires individuals to sacrifice food in order to obtain these, yet individuals on the upper bound poverty line (UBPL) can purchase both adequate food and non-food items (StatsSA, 20I4). The FPL is currently pegged at around ZAR32I per capita per month, LBPL is ZAR443 per capita per month, and the UBPL is ZAR620 per month per capita. The LBPL and UBPL are obtained using Ravallion cost of basic needs approach, where two different sets of non-food expenditure are obtained from two separate reference households and added to the poverty line to yield two sets of poverty (LPBL and UBPL) (StatsSA, 20I4).

In order to identify the likely causes of a household being vulnerable to poverty, we follow Glewwe, Gragnolati and Zaman (2000) and Justino 
and Litchfield (2002) approach of using a multinomial To begin, this study is focused on estimating the likelihood of a household being vulnerable to poverty in the near future. We thus, explore both rural and urban populations to get a deeper understanding of the factors that may likely contribute to vulnerability. Therefore, our analysis is limited to variables that may have an influence on the vulnerability of households or individuals to poverty. Consequently, a multinomial logit (MNL) model is used to estimate the probability of being vulnerable to poverty. Vulnerability to poverty was examined using the three poverty lines that are used by Statistics South Africa were: $0=$ the FPL (reflect extreme poverty), $I=L B P L$ and $2=U B P L$. The main reason for choosing such an approach is to identify the likelihood of households falling in between the poverty lines based on the cut- off in terms of income. The multinomial model takes the following specification.

$$
\operatorname{Prob}\left(Y_{i}=j\right)=\frac{e^{\beta_{j} X_{i}}}{\sum_{m=1}^{3} e^{\beta_{m X_{i}}}}, \quad j=
$$

\section{$1,2,3 \ldots . . M$. (eq7)}

All the parameters are estimated using the odds ratio (relative probabilities) regression model, although our approach differs in a

$$
\log \left[\frac{p\left\{y_{i}=j\right\}}{\left\{y_{i}=1\right\}}\right]=x_{i} \beta_{j} \text { and } \log \left[\frac{p\left\{y_{i}=j\right\}}{\left\{y_{i}=1\right\}}\right]=x_{i}\left(\beta_{j}-\beta_{k}\right)
$$

(eq8)

With the marginal effects as follows:

$$
\frac{p_{j}}{x_{i}}=p_{j}\left(\beta_{i}-\beta^{*}\right) \quad \text { with } \quad \beta^{*}=\sum_{k=1}^{j} p_{k} \beta_{k}
$$

(eq9)

Where $Y_{i}$ the outcome is faced by household $i$, and $X_{i}$ is the vector for household characteristics $l$, and $\beta_{j}$ is the vector of coefficients on $X_{i}$ applicable to a household in state $j$ and $\beta_{1}=0$. In this study, we estimate $K$ - $I$ slope coefficients plus an intercept for all the available alternatives. The model is estimated by the maximum likelihood, where all the probabilities of the observed outcomes enter the loglikelihood function. Nonetheless, households' movement between the poverty lines is estimated based on certain characteristics that may have a direct impact on household poverty like geographic location. Some areas without economic activity contribute to poverty due to fewer job opportunities, which affect household consumption patterns. Thus, based on the proposed poverty lines a three-tiered stratification in terms of vulnerability as follows in Table I was used.

Table I: Three-tiered stratification

\begin{tabular}{|l|l|}
\hline Sustained Poverty Escapes & $\leq \mathrm{UBPL}$ \\
\hline Vulnerable & $\geq \mathrm{FPL} \leq \mathrm{LBPL}$ \\
\hline Poor & $\geq \mathrm{FPL}$ \\
\hline
\end{tabular}

The determinants of poverty and vulnerability were investigated by focusing on household and geographic factors. In the equations, the base outcome is the UBPL (the household moving out of vulnerability). We control for characteristics of household head and regional variables. We have the following equation:

$$
\operatorname{Pr}\left(\text { povertyline }_{i, t}=1 \mid \beta, v_{i, t}\right)=f\left(\beta_{0}+\right.
$$$$
\left.\beta_{1} G o_{i, t}+\beta_{2} H H_{i, t}\right) \ldots .(\text { eql0) }
$$

Where $v_{i}=\left(1, \mathrm{Geo}_{i}, H H_{i}\right)$

povertyline $_{i}=$ the probability of a household $i$ being poor, vulnerable, and sustained poverty escapes;

$\mathrm{HH}=$ is a vector of variables defining the household head;

$\mathrm{Geo}=$ is a set of variables stating where a household resides, if whether it is located in urban or non-urban areas

In interpreting the results from the multinomial model, a risk ratio greater than $I$ indicates that a household has a higher risk ratio of the outcome relative to the base category of sustained poverty escape (UBPL). Food poverty (poor) and vulnerability (LBPL) are the outcomes that we compare to this reference category.
In order to identify the likely causes of a household being vulnerable to poverty, we follow the Foster, Greer and Thorbecke (FGT) class of poverty measures, exposure of poverty with greater inequality among the poor. Let us consider two incomes below the poverty line, poverty is said to be severe if one of the incomes is I per cent below the poverty line and one income is 99 per cent below the poverty line, in comparison with a situation with two incomes 50 per cent below the poverty line. The FGT takes the following form:

$$
P_{\propto}=\frac{1}{n} \sum_{i}\left(1-x_{i} / z\right)^{\propto} \Pi\left(x_{i} \leq\right.
$$

z)......

Wh....................................... .eqli)

Where $\alpha$ is a parameter that can be set at $0,1,2$ or more according to the importance attached to the poorest. If $\propto=0$ we get a headcount measure as follows:

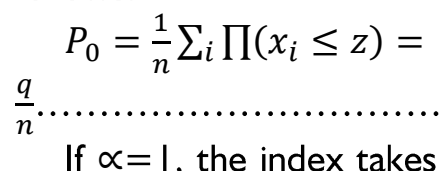

If $\propto=\mathrm{I}$, the index takes into account the distance of an individual/ household to poverty line using the poverty gap $\left(\mathbf{z}-x_{i}\right)$ as follows: 


$$
P_{1}=\frac{1}{n} \sum_{i}\left(1-x_{i} / z\right) \prod\left(x_{i} \leq\right.
$$

The poorer the individual, the larger their contribution to the value of the index, although the index is insensitive to income distribution among the poor. Consequently, it is insensitive to certain types of transfers among the poor. For $\propto=2$, the index measures sensibility of the distribution of income among the poor and takes the following form.

$$
P_{2}=\frac{1}{n} \sum_{i}\left(1-x_{i} / z\right)^{2} \prod\left(x_{i} \leq\right.
$$

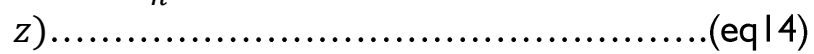

As suggested by Foster et al., (1984), the index can be decomposed because of its linear structure. For instance, let us assume we have a population between urban and rural areas. If $X$ represents the
Z).

income of the population, then $X$ can be partitioned as follows $\left(X=X^{-}+X^{R}\right)$. We the call $p$ the proportion of $X^{U}$ in $X$. The index is finally decomposed into

$$
P_{\propto}=p \frac{1}{n} \sum_{i=1}^{n_{U}}\left(\frac{z-x_{i}^{U}}{z}\right)^{\propto} \Pi\left(x_{i} \leq z\right)+(1-
$$

p) $\frac{1}{n} \sum_{i=1}^{n_{R}}\left(\frac{z-x_{i}^{R}}{z}\right)^{\propto} \prod\left(x_{i} \leq z\right)=p P_{\propto}^{U}+(1-$

p) $P_{\propto}^{R}$

Where $P_{\propto}^{U}$ is the index representing the urban population and $P_{\propto}^{R}$ represents the rural population. Table 2 provides a summary of the variables that were used in the regression analysis.

Table 2: Summary of variables

\begin{tabular}{|l|l|l|l|l|l|l|}
\hline Variable & Mean & Sd & Skewness & max & min & Kurtosis \\
\hline Prov (Province) & 5,288829 & 2,535005 &,$- 290387 I$ & 9 & $\mathrm{I}$ & $\mathrm{I}, 876 \mid 5 \mathrm{I}$ \\
\hline head_popgrp(Household head race) & $\mathrm{I}, 373779$ &, 8810796 & 2,299443 & 4 & $\mathrm{I}$ & 6,832962 \\
\hline head_sex (household head gender) & $\mathrm{I}, 417064$ &, $493085 \mathrm{I}$ &, 336404 & 2 & $\mathrm{I}$ & $\mathrm{I}, \mathrm{II} 3 \mathrm{I} 68$ \\
\hline head_age (household head age) & 47,55322 & $\mathrm{I} 5,74482$ &, 4157647 & $\mathrm{I} 10$ & 8 & 2,595324 \\
\hline Povline (poverty line) & 2,910566 &, 4083907 & $-4,40466 \mathrm{I}$ & 3 & $\mathrm{I}$ & 20,54465 \\
\hline Geo (Geo Location) & $\mathrm{I}, 389195$ &, 5734495 & $\mathrm{I}, \mathrm{I} 64745$ & 3 & $\mathrm{I}$ & 3,359297 \\
\hline Totmhinc (Total monthly income) & $\mathbf{7 0 4 8 , 6 0 6}$ & 9506,378 & 2,25068 & 40000 & 0 & $7,46605 \mathrm{I}$ \\
\hline
\end{tabular}

Results and discussions

Table 3: Summary of poverty lines in South Africa

\begin{tabular}{lllllll} 
& GHS 20I2 & \multicolumn{4}{l}{ GHS 20I5 } \\
AREA & FPL & LBPL & UBPL & FPL & LBPL & UBPL \\
\hline Urban & 487 & 77 & 15323 & 566 & 45 & 12452 \\
\hline Tribal areas & 376 & 92 & 7906 & 279 & 37 & 5962 \\
\hline Farm areas & 33 & 9 & 1027 & 20 & 1 & 910 \\
\hline Total & $\mathbf{8 9 6}$ & $\mathbf{1 7 8}$ & $\mathbf{2 4 2 5 6}$ & $\mathbf{8 6 5}$ & $\mathbf{8 3}$ & 19324 \\
\hline
\end{tabular}

Source: Own Calculations

As shown in table 3, households in urban areas poverty lines are higher than in other areas. This means that urban areas respondents have more income compared to other areas. The World Bank (2013) estimated that households would need to spend double the food poverty line per year to be out of poverty. However, in urban areas, the costs were over ZAR2000 and in rural areas ZARI00. This reflects that costs are higher in cities. In time we expect the poverty lines to shift based on economic changes. Firstly, the poverty lines are a reflection of the costs of purchasing food and non-food items. Thus, as price rises (inflation), nominal poverty lines are expected to follow suit. This is reflected in the 2015 survey, where there was a decline in the number of households falling in the UBPL and an increase in households falling in the FPL. Perhaps this is a replication of the volatile currency, which has contributed to higher food prices in the market, as well as a reduction in the purchasing power of the currency in the stated period.

This can be explained by using Quintiles Curves between the periods of 2012 to 2015. As shown in figure I we observe that the income share per quintile increased, in 2012, the maximum share was at ZAR20000, but in 2015, it jumped to ZAR40000. At the same time, the LBPL line decline from the 2012 level compared to 20I5, and the percentile of households in the UBPL increased. The income increases in households can be attributed to high inflation rates that were experienced in 2015 , which led to an increase in food prices. Thus, having ripple effects on salaries and other incomes. While price changes were expected due to a volatile currency, the devaluation of the South African Rand to close to US\$=ZARI8 in 2015 had a serious strain in the labour market, where wage and salary protests increased in the 2014/15 period. The strikes were 
mainly emanating from the manufacturing and mining sectors which contribute over 20 per cent of South Africa's GDP (StatsSA, 2016). Whereas these strikes were concentrated in these sectors, the effects they had in the economy was devastating, with a number of fatalities and destruction of public property. As a result, there was a decline in economic activity, and other economic disturbances contributed to this situation.

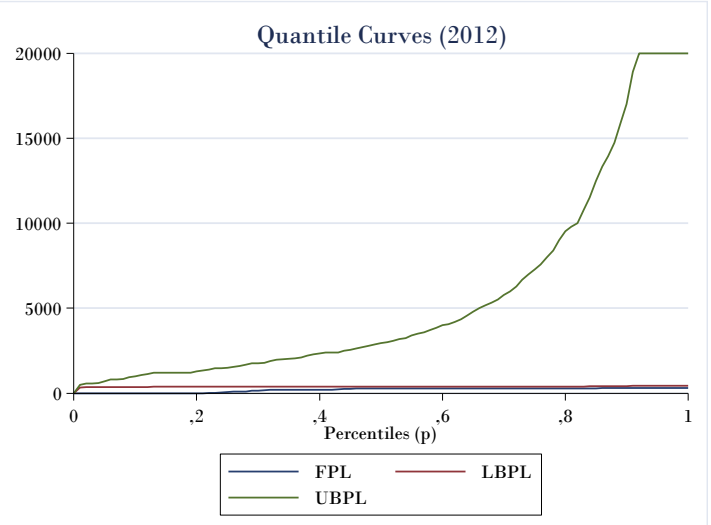

Figure I: Quintile Curves

In terms of the income distribution, we can observe that figure 2 is organised based on quintile, race and province. The mean income was lower than ZAR80000 in 2012, with around 6/9 Provinces approaching the maximum income. The Eastern Cape Province and the North West Province regarded as one of the poorest provinces were ranked lower in terms of income per household (<ZAR50000). Yet, the Gauteng and Mpumalanga Provinces were neck and neck in terms of the income distribution. In the relation of population

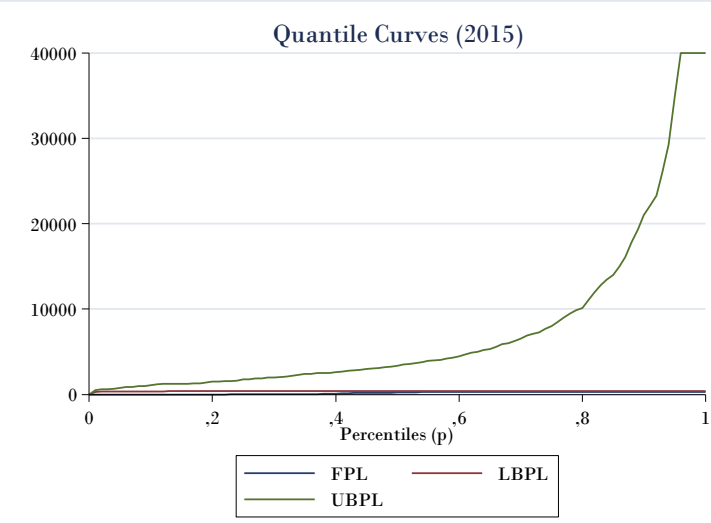

Source: Author calculations

groups, we note that whites followed by Indians had the highest income per households in every quintile and province. In provinces such as the Eastern Cape and Limpopo, we note a change in the $5^{\text {th }}$ quintile (highest) were the whites come ahead of the coloureds and blacks, surprising no Indians fall in that quintile. Briefly, it can be summed that blacks and coloureds rank lowest in every quintile regardless of the province, demonstrating that the two races are the most likely to be more vulnerable to poverty than other races.

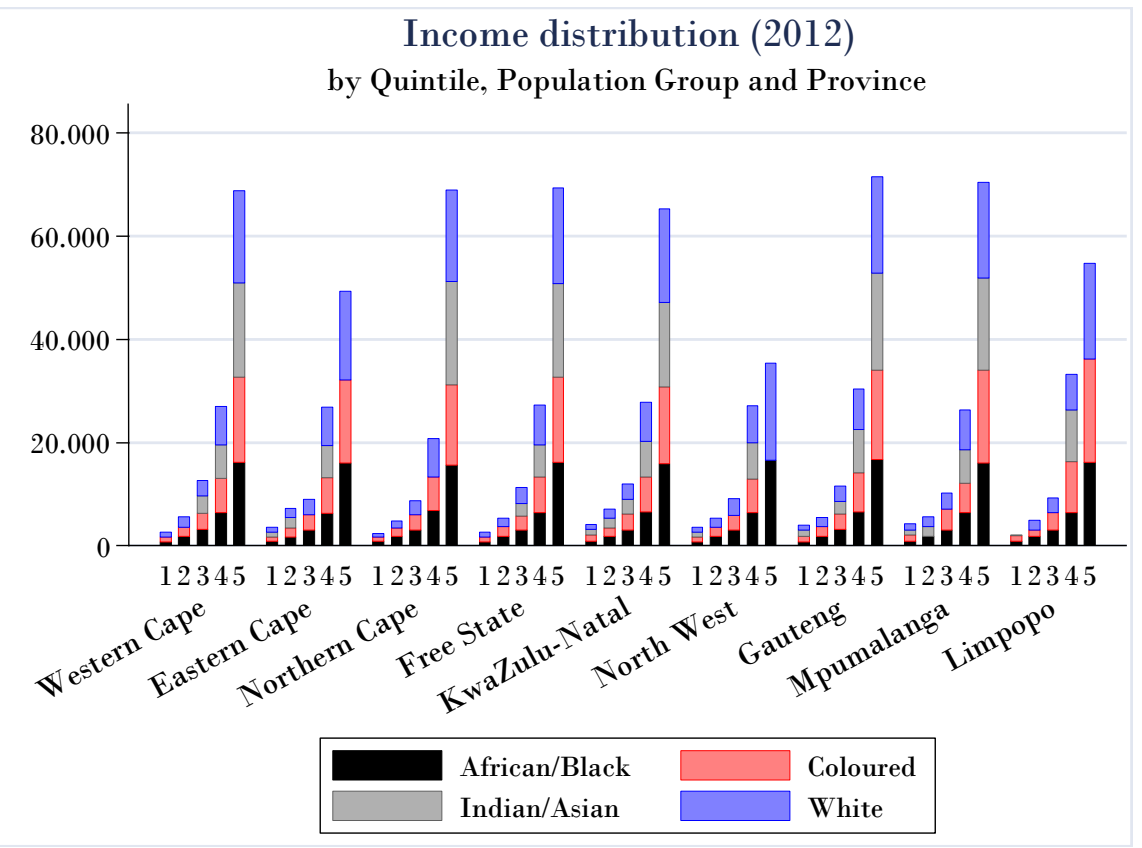

Figure 2: Income distribution (20I2)

Source: Author calculations

In 2015, we note that the Eastern Cape lags behind in terms of income distribution with over ZAR 50000
(2012 figures) to approximately ZAR 70000. On the other hand, the Northern Cape Province fell to 
around ZAR 60000 from over ZAR65000, making it the lowest ranked province. Likewise, the income distribution means increased from ZAR80000 (20I2) to ZARI00000, demonstrating that households highlighting that income distribution is skewed to those provinces. The Gauteng and Western Cape Provinces contribute to over 54 per cent of the South Africa Gross National Product (StatsSA, 2016). Thus, income distribution is expected to be influenced by the skewed economic activities in those provinces compared to the rest. In terms of income distribution per province, there has been an improvement from incomes have tremendously increased compared to the 2012 period. In the 2015 period, Gauteng, Western Cape and the Free State Provinces had mean household incomes surpassing ZARI00000, 2012 , although between population groups inequality has increased. It has been noted here that Whites and Indians have increased their income shares as shown in the $5^{\text {th }}$ Quintile, and it is a trend in almost every province with the exception of the Northern Cape, where the Indians are replaced by the Coloureds. This is shown in figure 3.

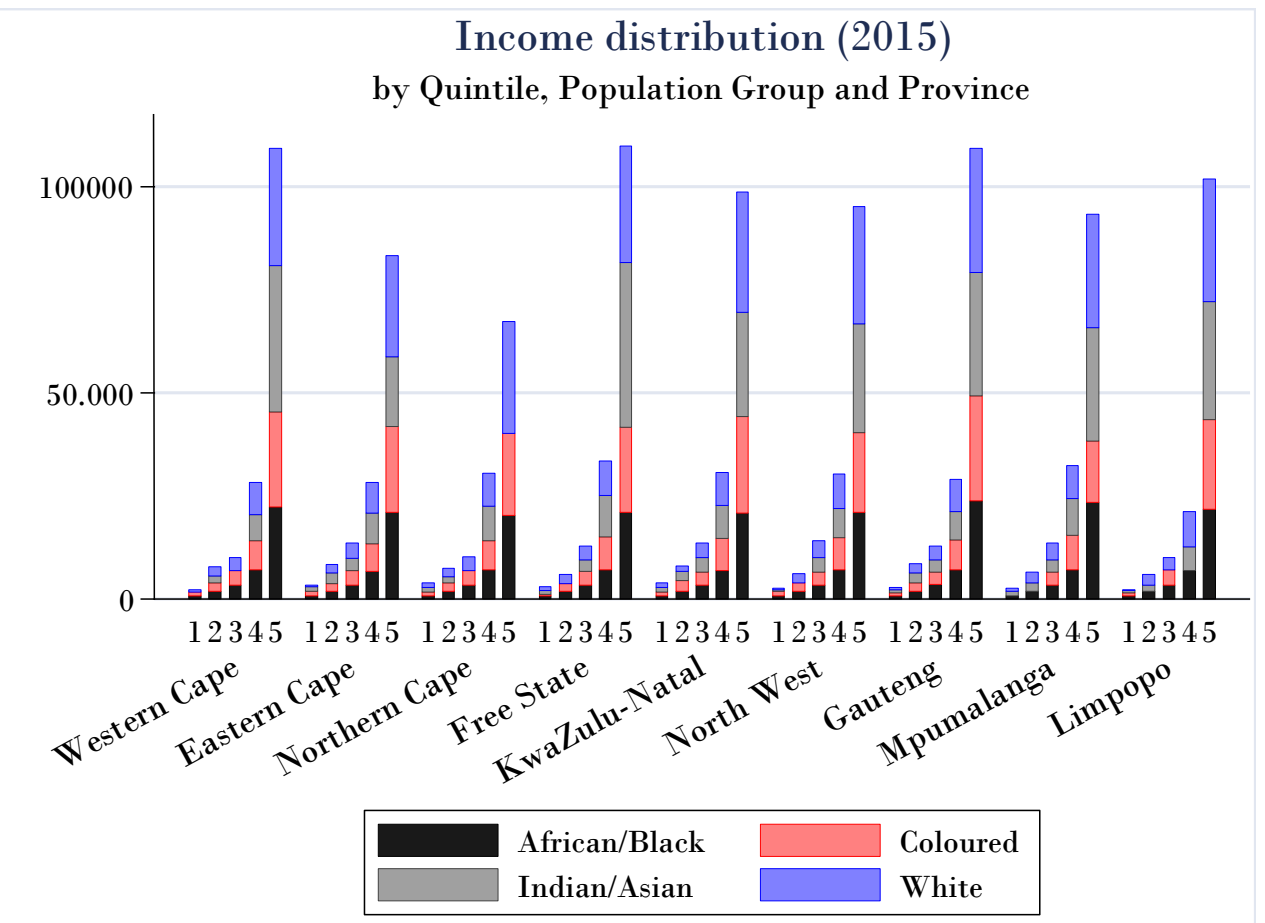

Figure 3: Income distribution (20I5)

To get a deeper insight on inequality, we estimate Generalised Lorenz Curves for both periods as shown in figure 4. We strongly focus on urban (metro) vs non-urban areas (non-metro). The Generalised Lorenz Curve (GLC) provides
Source: Author's calculations

information on inequality as measured by the partial mean ratio. Thus, inequality ordering is represented by the generalised Lorenz curve, where the higher generalised Lorenz curve indicates unambiguously lower inequality according to the poverty gap measure.

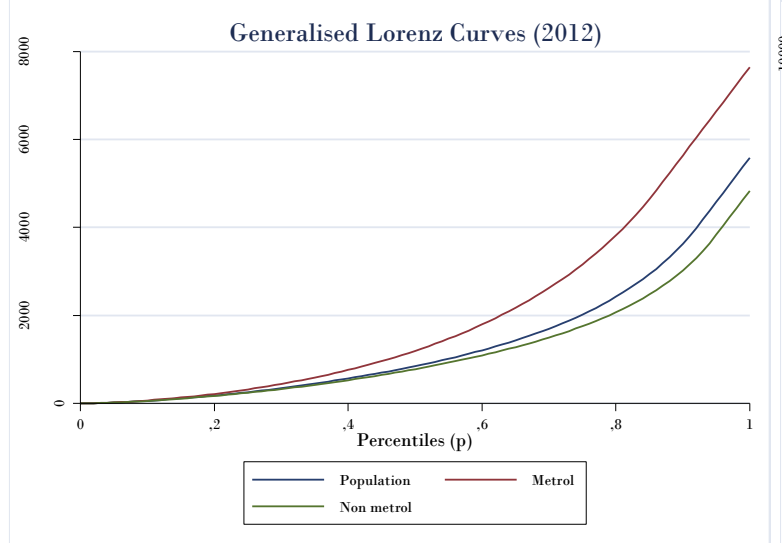

Figure 4: Generalised Lorenz Curve



Source: Author's calculations

http://aps.journals.ac.za 
In this case, we note that the GLC in 2012 and 2015 reveal that the curve Metro (Urban) dominates both the Non-Metro (Non-Urban) and population curves.

Suggesting that inequality is lower in urban areas compared to non-urban areas. At the same time, non-urban areas are worse in terms of inequality compared to the general population. In simple terms, households staying in non-urban areas are more vulnerable to poverty than those in urban areas are. However, the GLC in 2015 shows an improvement in terms of inequality from the 2012 period, with the gap between curves declining between urban areas and non-urban areas.

The FGT elasticities were then estimated according to Provinces. As shown in table 4, Gauteng, Eastern Cape, Limpopo and the Western Cape Provinces had a large share of over 10 per cent each for the whole population sampled in 2012. The marginal impact on inequality was high for the Gauteng (8\%), the KwaZulu Natal and the Western Cape $(6 \%)$ Provinces. Yet, in terms of the marginal impact on poverty, Limpopo, KwaZulu Natal and Gauteng provinces showed an impact of over 6 per cent. Within Provinces, the marginal impact on inequality was 49 per cent, and poverty was at 55 per cent. Overall, the marginal impact on equality was 5 I per cent and the marginal impact on poverty was 58 per cent. Striking differences were noted in the elasticity between provinces, where Limpopo, North West, Free State and Eastern Cape showed a higher elasticity's ( $>10$ per cent) compared to the population ( 10 per cent). The four provinces showed their sensitivity to inequality and poverty impacts.

Table 4 FGT elasticities with regards to within groups' components of inequality (20I2)

Poverty and inequality indices

\begin{tabular}{|c|c|}
\hline Indices & Estimate \\
\hline FGT & 0,057771 \\
Gini & 0,513250 \\
\hline
\end{tabular}

\begin{tabular}{|c|c|c|c|c|}
\hline Group & $\begin{array}{l}\text { Population } \\
\text { Share }\end{array}$ & $\begin{array}{l}\text { Marginal } \\
\text { impact on ineq. }\end{array}$ & $\begin{array}{l}\text { Marginal } \\
\text { impact on pov. }\end{array}$ & Elasticity \\
\hline $\begin{array}{l}\text { 1: Western Cape } \\
\text { 2: Eastern Cape } \\
\text { 3: Northern Cape } \\
\text { 4: Free State } \\
\text { 5: KwaZulu-Natal } \\
\text { 6: North West } \\
\text { 7: Gauteng } \\
\text { 8: Mpumalanga } \\
\text { 9: Limpopo }\end{array}$ & $\begin{array}{l}0,117712 \\
0,124246 \\
0,058916 \\
0,082074 \\
0,165545 \\
0,084332 \\
0,144732 \\
0,101960 \\
0,120483\end{array}$ & $\begin{array}{l}0,060964 \\
0,050025 \\
0,029080 \\
0,040967 \\
0,080382 \\
0,041449 \\
0,087936 \\
0,049071 \\
0,047042\end{array}$ & $\begin{array}{l}0,050985 \\
0,064568 \\
0,032446 \\
0,050806 \\
0,090677 \\
0,052831 \\
0,083487 \\
0,052282 \\
0,070707\end{array}$ & $\begin{array}{r}7,430095 \\
11,466991 \\
9,912634 \\
11,018141 \\
10,022114 \\
11,323839 \\
8,434784 \\
9,465691 \\
13,353618\end{array}$ \\
\hline within & . & 0,487044 & 0,548789 & 10,010597 \\
\hline Between & . & 0,014097 & 0,006868 & 4,328490 \\
\hline Population & 1,000000 & 0,513250 & 0,582760 & 10,087484 \\
\hline
\end{tabular}

Source: Author's calculations

In 2015, we note that the Gini index increased from $0.5 \mathrm{I}(20 \mathrm{I})$ to 0.58 pointing that inequality increased in Provinces, as well as the poverty FGT index increased from 0.57 per cent to 0.62 per cent in 2015. In terms of population share, Gauteng, KwaZulu Natal, Eastern Cape and Limpopo provinces provided more households for the sample. Therefore, in standing on a marginal impact on inequality, we note that Gauteng (16\%) and KwaZulu Natal (8\%) showed a high impact compared to other provinces. Yet, in terms of marginal impact on poverty, we note that the same two provinces dominate, maybe because of the skewed sampled households, which were more than in other provinces. 
Table 5: FGT elasticities with regards to within groups' components of inequality (20I5)

Poverty and inequality indices

\begin{tabular}{|c|c|}
\hline Indices & Estimate \\
\hline FGT & 0,062620 \\
Gini & 0,580305 \\
\hline
\end{tabular}

Marginal Impact \& Elasticities By Groups

\begin{tabular}{|c|c|c|c|c|}
\hline Group & $\begin{array}{l}\text { Population } \\
\text { Share }\end{array}$ & $\begin{array}{l}\text { Marginal } \\
\text { impact on ineq. }\end{array}$ & $\begin{array}{l}\text { Marginal } \\
\text { impact on pov. }\end{array}$ & Elasticity \\
\hline $\begin{array}{l}\text { 1: Western Cape } \\
\text { 2: Eastern Cape } \\
\text { 3: Northern Cape } \\
\text { 4: Free State } \\
\text { 5: KwaZulu-Natal } \\
\text { 6: North West } \\
\text { 7: Gauteng } \\
\text { 8: Mpumalanga } \\
\text { 9: Limpopo }\end{array}$ & $\begin{array}{l}0,095891 \\
0,137786 \\
0,046797 \\
0,059222 \\
0,182434 \\
0,064568 \\
0,217894 \\
0,082486 \\
0,112923\end{array}$ & $\begin{array}{l}0,061877 \\
0,052686 \\
0,021561 \\
0,031918 \\
0,087377 \\
0,031155 \\
0,163411 \\
0,046065 \\
0,048357\end{array}$ & $\begin{array}{l}0,050653 \\
0,067751 \\
0,023995 \\
0,043437 \\
0,116223 \\
0,045319 \\
0,168703 \\
0,050607 \\
0,076781\end{array}$ & $\begin{array}{r}7,586174 \\
11,916874 \\
10,313466 \\
12,611228 \\
12,326477 \\
13,480451 \\
9,567227 \\
10,180896 \\
14,714243\end{array}$ \\
\hline within & .1 & 0,544378 & 0,643470 & 10,953953 \\
\hline Between & $\cdot$ & 0,024208 & 0,008563 & 3,278028 \\
\hline Population & 1,000000 & 0,580305 & 0,703475 & 11,234022 \\
\hline
\end{tabular}

Source: Author's calculations

However, we note that elasticities increased in every province from 2012 figures, although the within groups elasticity increased marginally by less than I per cent. While within the marginal impact on inequality increased from 48 per cent (20/2) to 54 per cent (2015). It was a huge increase in line with marginal impact on poverty, which increased from 54 per cent (2012) to 64 per cent (2015). This contributed to an overall population marginal impact on poverty increasing by 8 per cent in 2015 and the marginal impact on poverty increasing by 12 per cent as illustrated in table 5 . Consequently, poverty and inequality increased amongst provinces.

We note that urban areas contributed 27 per cent of the total FGT, while the non-urban areas contributed 73 per cent in 2012. Thus, we can safely say poverty is higher in non-urban areas as shown in table 6.

Table 6: FGT index by groups (20I2)

Decomposition of the FGT index by groups

Poverty index : FGT index

Household size : hholdsz

Group variable : Metro

Parameter alpha : 1,00

\begin{tabular}{|l|rrrr|}
\hline Group & FGT index & \multicolumn{1}{c}{$\begin{array}{c}\text { Population } \\
\text { share }\end{array}$} & $\begin{array}{c}\text { Absolute } \\
\text { contribution }\end{array}$ & $\begin{array}{c}\text { Relative } \\
\text { contribution }\end{array}$ \\
\hline Metro1 & 0,140256 & 0,384165 & 0,053882 & 0,266225 \\
Non metro1 & 0,004875 & 0,006056 & 0,002060 & 0,008765 \\
& 0,241152 & 0,615835 & 0,148509 & 0,733775 \\
\hline Population & 0,003075 & 0,006056 & 0,002355 & 0,008765 \\
& 0,202391 & 1,000000 & 0,202391 & 1,000000 \\
& 0,002717 & 0,000000 & 0,002717 & 0,000000 \\
\hline
\end{tabular}

Source: Author's calculations

In 2015 we note a similar trend, where the urban areas contribute 35 per cent of FGT, while the nonurban areas contribute 65 per cent. Poverty has increased in urban areas compared to non-urban areas, where the majority of the population lives as revealed in table 7. However, the non-urban areas continue to have a sizable contribution to the overall poverty. 
Table 7: FGT index by groups (20I5)

Decomposition of the FGT index by groups

Poverty index : FGT index

Household size : hholdsz

Group variable : Metro

parameter alpha: 1,00

\begin{tabular}{|l|crrr|}
\hline Group & FGT index & $\begin{array}{c}\text { Population } \\
\text { share }\end{array}$ & $\begin{array}{c}\text { Absolute } \\
\text { contribution }\end{array}$ & $\begin{array}{c}\text { Relative } \\
\text { contribution }\end{array}$ \\
\hline Metro & 0,154989 & 0,415975 & 0,064472 & 0,345208 \\
Non-Metro & 0,000000 & 0,000000 & 0,000000 & 0,000000 \\
& 0,209392 & 0,584025 & 0,122290 & 0,654792 \\
Population & 0,000000 & 0,000000 & 0,000000 & 0,000000 \\
& 0,186762 & 1,000000 & 0,186762 & 1,000000 \\
& 0,000000 & 0,000000 & 0,000000 & 0,000000 \\
\hline
\end{tabular}

We then set the FGT at alpha $=0$, in 2012 we note that there was a huge poverty gap between the Western Cape Province and the rest of provinces when the poverty line is estimated to be at around ZARI 200, although such a gap was evident when the poverty line was over ZAR700. This means that as the poverty line increases so does poverty headcount ratio increases in every province. This is shown in figure 5 .

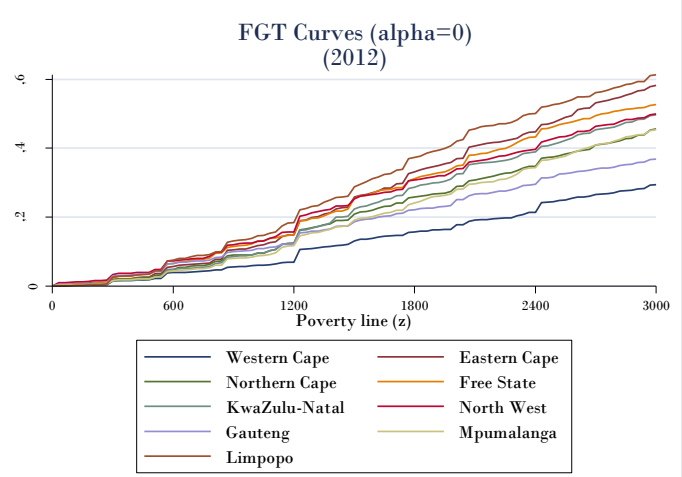

Figure 5: FGT curves

On the hand, in 2015 the differences in poverty become evident when the poverty line is set at around ZARI800, with the Western Cape revealing a huge headcount poverty gap from the rest of the provinces.

Decomposing poverty by provinces reveals that the Gauteng, Limpopo and the Eastern Cape provinces contributed more to the overall poverty as demonstrated in figure 6 . At the same time, we realise that in terms of poverty, the Eastern Cape

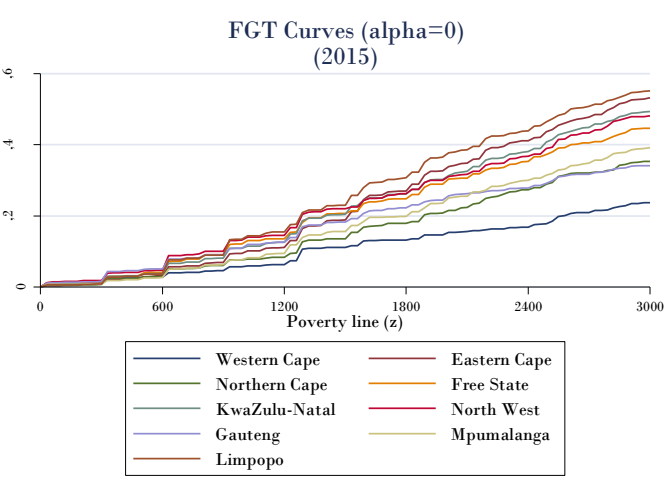

\section{Source: Author's calculations}

Province has shown no changes since 20/2. Yet, the Gauteng Province has shown a shift using 2015 survey data, from being second least poor to be the fourth poorest Province. In short, the Eastern Cape dominates all other provinces in terms of income distribution up to the maximum poverty line, meaning that the poverty gap of income distribution is always high in the Eastern Cape than any province in South Africa.

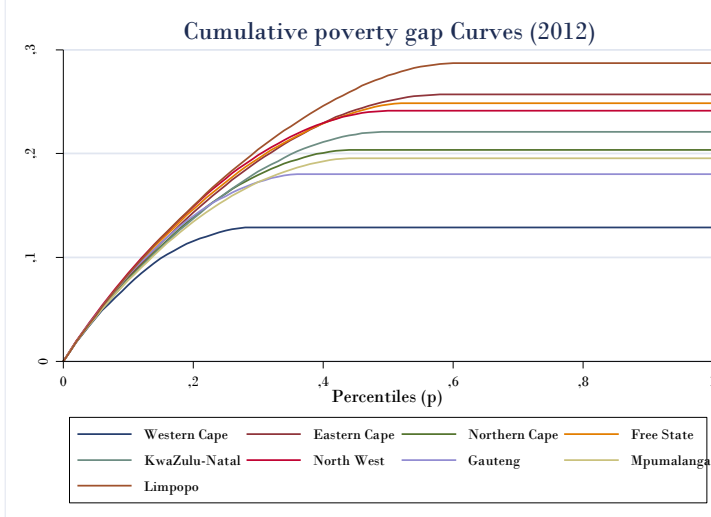

Figure 6: Poverty gap curves

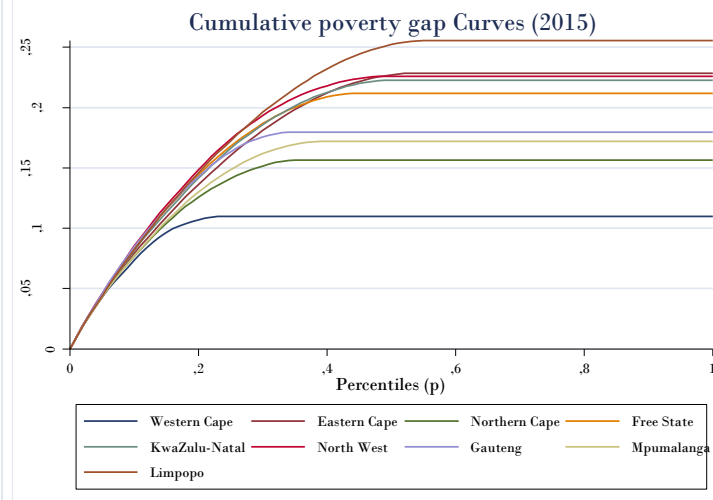

Source: Author's calculation 
While other provinces have shown improvements in terms of the income distribution, the Gauteng province has shown a regressing income distribution in the 2015 period, with poverty rising from the 2012 estimates. The Western Cape maintains its position as the province with the least poor households in both periods.

Vulnerability among population groups is evident as shown in figure 7. We split population groups in terms of a population group, and estimate exposure to hazard. In this case, we estimate the likelihood of population groups falling poverty over time. In 20I2, black Africans showed high levels of vulnerability in terms of poverty exposure followed by coloured, and Indians. We observe a similar trend in 2015 , but this time there is a sudden rise on the coloured curve where it intersects with the black Africans curve. This illustrates that poverty exposure has risen for coloureds compared to other races. We also notice a decline in vulnerability on Indians compared to the 2012 estimates. However, in 2015 there are low levels of vulnerability in comparison to other groups. While poverty level has declined throughout the years, whites in the 2015 survey show high levels of vulnerability compared to the 2012 estimates. Suggesting that income distribution has changed tremendously in both periods for every group, with more population groups either low-income earners or high-income earners. This finding is in line with Zizzamia, Schotte, Leibbrandt and Ranchhod (2015) study, which pointed that middle class in South Africa, is smaller than previously estimated, and has been sluggish since 1993. The study went on to claim that previous households that fell in the middle class have fallen to poverty throughout the years. This is very evident, with StatsSA (20I6) admitting that while poverty levels have declined, inequality has tremendously increased in South Africa.

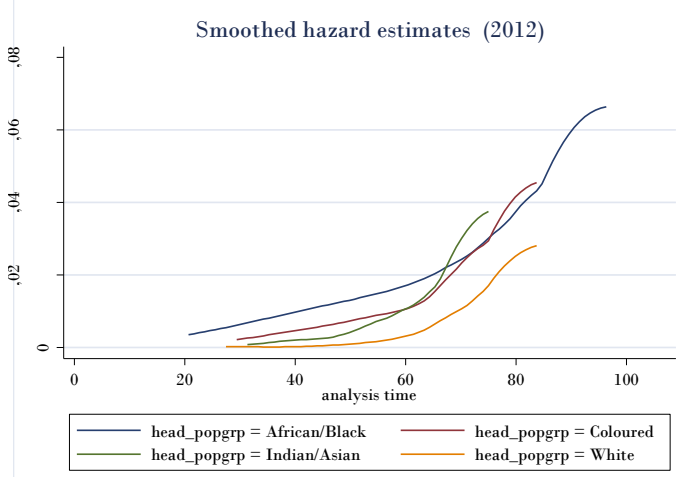

Figure 7: Smoothed hazard estimates

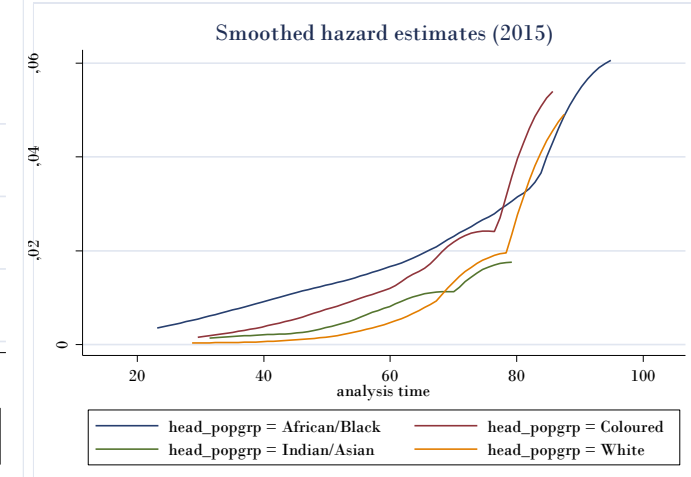

Source: Author's calculations

\section{Multinomial logit results}

A relative risk (rrr) of less than one means that an increase in variable $X$ increases the probability that the household falling in the reference category (base category), yet, an rrr more than one implies an increase in the probability of the household being in the alternative state. Households located in tribal/ traditional areas are more at risk of being in deprivation compared to urban areas or farm areas. These households are located in rural areas dominant Provinces like the Eastern Cape, North West, Mpumalanga, Limpopo and the KwaZulu Natal. We run a series of regressions and exclude provinces in both periods from the empirical analysis because the results show skewness to provinces with households in tribal areas, suggesting that in both periods there was no significant change in terms of vulnerability within Provinces. Thus, we at least focus on geographic location as a measure on which areas are more vulnerable. Results in table 8 indicate variations on the risk ratio of being poor relative to sustained poverty escapes.
FPL

Geo- this is the relative risk ratio for a one-unit change in geographic location for FPL relative to the UBPL given other variables in the model are held constant. If income were to increase by a unit, the relative risk for FPL relative to UBPL will decrease by 0.89 in farm areas given other variables are constant. In short, we can say if the geographic location were to change their income, there would be expected to fall in the UBPL compared to the FPL. It seems staying in tribal area is associated with an increased risk ratio of FPL relative to the UBPL in both periods. This could be a reflection of income distribution throughout South Africa, were tribal areas have the most vulnerable households compared to many areas. The variable is statistically significant in both periods. Yet, those residing in farm areas in 2015 were associated with a decreased risk ratio of FPL relative to the UBPL, suggesting that farm areas households in 2015 were likely to be out of food poverty. 
Table 8: Multinomial model results

\begin{tabular}{|c|c|c|c|c|c|c|c|c|c|c|c|c|c|}
\hline \multirow{2}{*}{$\begin{array}{l}\text { Variables } \\
\text { Povline }\end{array}$} & \multicolumn{3}{|l|}{2012} & \multicolumn{3}{|l|}{2015} & \multirow{2}{*}{\begin{tabular}{|l|} 
Variables \\
Povline \\
\end{tabular}} & \multicolumn{3}{|l|}{2012} & \multicolumn{3}{|l|}{2015} \\
\hline & RRR & $\mathbf{Z}$ & $P>z$ & RRR & $\mathbf{Z}$ & $P>z$ & & RRR & $\mathbf{Z}$ & $\mathrm{P}>\mathrm{z}$ & RRR & $\mathbf{z}$ & $P>z$ \\
\hline \multicolumn{7}{|c|}{ FPL (POOR) } & \multicolumn{7}{|c|}{ LBPL (VULNERABLE) } \\
\hline \multicolumn{7}{|l|}{$\overrightarrow{\mathrm{Geo}}$} & \multicolumn{7}{|l|}{ Geo } \\
\hline Tribal areas & 1,31 & 3,33 & $0,00 \mid$ I*** & $\mathrm{I}, 17$ & 1,67 & $0,095 *$ & Tribal areas & $\mathrm{I}, 75$ & 3,20 & $0,00 I^{* * * *}$ & 1,60 & 1,80 & $0,072 *$ \\
\hline Farm areas & 0,89 & $-0,61$ & 0,544 & 0,47 & $-3,23$ & $0,00 \mid * * * *$ & Farm areas & 1,35 & 0,84 & 0,403 & 0,23 & $-1,46$ & 0,144 \\
\hline \multicolumn{7}{|c|}{ head_popgrp } & \multicolumn{7}{|c|}{ head popgrp } \\
\hline Coloured & 0,56 & $-3,84$ & $0,000 * * *$ & 0,67 & $-2,52$ & $0,0 \mid 2 *$ & Coloured & 0,267 & $-2,58$ & $0,010 *$ & 2,45 & $-0,02$ & 0,986 \\
\hline Indian/Asian & 0,21 & $-3,08$ & $0,002 * * *$ & 0,30 & $-2,86$ & $0,004 * * *$ & Indian/Asian & 1,09 & $-0,02$ & 0,980 & 2,03 & $-0,01$ & 0,993 \\
\hline White & 0,09 & $-6,34$ & $0,000 * * *$ & 0,62 & $-2,72$ & $0,007 * * *$ & White & 0,075 & $-2,57$ & $0,010 *$ & 0,212 & $-1,53$ & 0,125 \\
\hline \multicolumn{7}{|l|}{ head sex } & \multicolumn{7}{|l|}{ head sex } \\
\hline Female & 0,89 & $-1,57$ & 0,117 & 0,83 & $-2,57$ & $0,010 *$ & Female & 0,80 & $-1,40$ & 0,163 & 0,45 & $-3,12$ & $0,002 * * *$ \\
\hline head_age & 0,97 & -14 & $0,000 * * *$ & 0,97 & $-10,83$ & $0,000 * * *$ & head age & 0,96 & $-7,56$ & $0,000 * * * *$ & 0,95 & $-5,40$ & $0,000 * * * *$ \\
\hline \multicolumn{7}{|l|}{ Metro } & \multicolumn{7}{|l|}{ Metro } \\
\hline Non metrol & 1,11 & 1,14 & 0,256 & 0,85 & $-1,92$ & $0,055^{*}$ & Non metrol & 1,53 & $|, 8|$ & 0,070 & 1,26 & 0,81 & $0,4 \mid 5$ \\
\hline cons & 0,18 & $-14,2$ & $0,000 * * * *$ & 0,19 & $-14,57$ & $0,000 * * * *$ & cons & 0,032 & $-12,25$ & $0,000 * * *$ & 0s,035 & $-9,01$ & 0,000 **** \\
\hline \multicolumn{14}{|c|}{ UBPL (reference category) } \\
\hline Note $*$ & & & & & & & & & & & & & \\
\hline
\end{tabular}


Similar, nonblack African population groups were associated with a decreased risk ratio of FPL relative to UBPL. The population variables in both periods (2012 and 2015) revealed that nonblack population groups were likely to be out of food poverty in comparison to black Africans in both periods. This is a known fact that most poor households are mainly black Africans residing in tribal or traditional areas (rural areas). This finding reveals that little has changed for black African in terms of income poverty. Female-headed households' have a statistically significant less risk of falling into the poor category in 2015 compared to their male counterpart. This reflects that women are slowly moving out of food poverty. Age of household head seems to be showing a less risk of falling in the food poverty line, pointing that younger people are less likely to be in food poverty compared to the older. This is a true reflection of income dynamics in South Africa, where the majority of older people are relying on government grants for their livelihoods. Yet, young people are relying on income generated through salaries or other incomes for their livelihoods. Nonetheless, literature is divided concerning the effect of age on poverty and vulnerability.

Households residing in non-metro (non-urban) areas showed a low relative risk of falling into food poverty in 2015, pointing that there has been an improvement in terms of income distribution between urban and non- urban areas. It is important to point that in terms of none urban areas, farm areas showed fewer income disparities with urban areas, highlighting that most of the households who are likely moved out of food poverty in 2015 were in farm areas.

\section{UBPL}

The geographic location variable (Geo) shows that if income were to increase by one unit in geographic location for LBPL relative to UBPL given other variables are constant, the relative risk for LBPL to UBPL would be expected to increase by a factor of I.75 given other variables are constant. In 2012 and 2015, tribal areas households showed a relatively high risk of falling into vulnerability. Yet, farm areas although the variable was insignificant, showed some improvement; in 2012, there was a high risk of falling in the vulnerability group, although in 2015 we note a change with a likelihood of falling in the UBPL. Thus escaping poverty and vulnerability.

Yet, in terms of population groups, coloured and whites had a relatively high risk of moving out of vulnerability compared to black Africans in 2012 . While in 20I5, in terms of gender female showed a relatively high risk of moving out of vulnerability compared to males. With age having a similar 4813 influence as noted before. In both periods, nonmetro areas have a statistically significant increase in the relative risk of vulnerability. A key change faced by non-urban households is having a few sources of income. In our analysis, an increase in the likelihood of living in non-urban areas increases the risk of being vulnerable in both periods under study.

The analysis of this study reveals several important areas of focus on the likelihood of households moving to sustained escape from poverty. A number of determinants have differential effects on vulnerability and poverty when disaggregated by sex, suggesting that different approaches are needed to identify vulnerability in a broader sense. While poverty has declined national, inequality has increased as revealed by StatSA (2016).

\section{Conclusion and recommendations}

Although South Africa is a middle-income per capita economy, poverty and vulnerability are still rife. Incidences of poverty are imminent in specific areas or provinces. The study revealed that there was a reduction of households falling in the middle poverty line. This signifies that poverty is either extreme or low in certain households or provinces. On the other hand, factors such as race, location and gender had an impact on the poverty status. In numerous cases, black African households residing in non-urban areas were the most exposed to poverty and vulnerability, highlighting that since democratisation, a little has been done in bridging the poverty gap between races. This finding is cemented by the fact that whites (both in urban and non-urban areas) have very low incidences of poverty. This showed that income was skewed to one race, with most blacks relying on pensions and government grants.

The implication of these findings is that vulnerability is more prominent to a household facing food poverty. Firstly, policymakers should focus on anti-poverty strategies that address food security, especially in rural areas. This means that the government should focus on developing rural areas where a large number of households are facing food poverty. The findings revealed that female-headed households mainly in the rural areas were the most vulnerable to poverty. Gendered poverty has been a problem in South Africa as revealed by Rogan (2015) who concluded that labour market policies are discriminatory. Thirdly, the government should focus on opening the economy to every race, evidence from the survey revealed that income was skewed to favour certain races. For instance, the Western Cape Province, which is mainly dominated by whites, had lower rates of poverty compared to other provinces, although within race estimates; suggest that the gap in income distribution between whites and blacks 
was very high. This paper calls for policy instruments that target different income groups; this can be in form of social protection schemes for the poor and farmer insurance to prevent mainly rural households from falling into poverty in situations where there are negative shocks. A better policy would have a mix of strategies that can target vulnerable households and poverty at the same time.

\section{References}

Ajay, T, and Rana, H. 2005. 'Conceptualising and Measuring Poverty as Vulnerability: Does It Make a Difference?' ERD Policy Brief Series No. 4I. Manila: Asian Development Bank.

Alwang, J., Siegel, P.B., and Jorgensen, S.L. 200I. "Vulnerability: A View from Different Disciplines." Social Protection Discussion Article No. 0015. The World Bank: Washington, D.C.

Carter, M.R., and Barrett, C.B. 2006."The Economics of Poverty Traps and Persistent Poverty: An Asset-Based Approach." Journal of Development Studies 42(2): 178199.

Chambers, R. 1989. Vulnerability, Coping and Policy. IDS Bulletin, 20.

Chaudhuri, S. 2003. Assessing vulnerability to poverty: concepts, empirical methods and illustrative examples. Department of Economics, Columbia University.

Chaudhuri, S., Jalan, J., and Suryahadi, A. 2002. Assessing Household Vulnerability to poverty from cross-sectional data. A methodology and estimates from Indonesia, Discussion Paper No. 0102-52. New York: Columbia University.

Christiaensen, L., and Subbarao, K. (2005). Towards an Understanding of Household Vulnerability in Rural Kenya. Journal of African Economies I4 (4): 520-58.

Devereux, S. 1999. Making Less Last Longer: Informal Safety Nets in Malawi. IDS Discussion Article 373. Institute of Development Studies, London

Ellis, F. 1993. Peasant Economies: Farm Households and Agrarian Development. Cambridge University Press.

Ferreira, F.H.G., Messina, J., Rigolini, J., López-Calva, L.F., Lugo, M.A., and Vakis, R. 2013.Economic Mobility and the Rise of the Latin American Middle Class. Washington, DC: World Bank

Gilbert, C.L., and Varangis, P. 2004. Globalization and international commodity trade with specific reference to the West African cocoa producers. NBER Working Article 9668.

Glewwe, P., Gragnolati, M., and Zaman, H. 2000. Who Gained from Vietnam's Boom in the 1990s? An Analysis of Poverty and Inequality Trends.
World Bank Working Paper 2275, Washington, D.C.

Golaz, V., and Rutaremwa, G. 20I I. The vulnerability of older adults: what do census data say? An application to Uganda. African Population Studies, 25(2): 605-621.

Jalan, J., and Ravallion, M.1999. Do Transient and Chronic Poverty in Rural China Share Common Causes?, Paper presented at IDS/IFPRI Workshop on Poverty Dynamics, April 1999, Institute of Development Studies, Brighton.

Jalan, J., and Ravallion, M. 1998. Transient Poverty in Postreform Rural China. Journal of Comparative Economics 26( 2): 338-357.

Jalan, J., and Ravallion, M. 1997. Are the Poor Less Well-Insured? Evidence on Vulnerability to Income Risk in Rural China. World Bank Policy Research Working Paper No 1863.

Justino, P., and Litchfield, J. 2002. Economic Exclusion and Discrimination. An Issues Article Prepared for the Minority Rights Group International. Brighton: University of Sussex. Forthcoming.

Meyer, D.F., and Nishimwe-Niyimbanira, R. 2016. The impact of household size on poverty: An analysis of various low income townships in the Nothern Free State Region, South Africa. African Population Studies 30(2): 2283-2295.

McKay, A., and Lawson, D. 2003. Assessing the extent and nature of chronic poverty in lowincome countries: Issues and Evidence. World Development, 3 I (3), 425-440.

Narayan, D., Chambers, R., Shah, M. K., and Petesch, P. 2000. Voices of the Poor: Crying Out for Change. Washington DC: Oxford University Press for the World Bank

Pritchett, L., Suryhadi, A., and Sumarto, Y.S. 2000. Quantifying Vulnerability to Poverty: A Proposed Measure with Application to Indonesia. World Bank Policy Research Working Article 2437.

Reardon, T. 1997. Using Evidence of Household Income Diversification to Inform Study of the Rural Nonfarm Labor Market in Africa. World Development 25(5):735-747

Sharma, M., Burton, I., van Aalst, M., Dilley, M., and Acharya, G. 2000. Reducing Vulnerability to Environmental Variability: Background Article for the Bank's Environmental Strategy. The World Bank: Washington, D.C.

StatSA. 2014. Quarterly Labour Force Survey. Statistics South Africa: Pretoria.

StatsSA. 2016. Quarterly Labour Force Survey. Statistics South Africa: Pretoria

Vakis, R., Rigolini, J., Lucchetti, L. 20I5. Left behind: chronic poverty in Latin America and the 
Caribbean, Overview. Washington, DC: World Bank

Winters A., McCulloch, N., and McKay, A. 2004. "Trade Liberalization and Poverty: The Evidence So Far". Journal of Economic Literature 42: 72II5.

Zhang, Y., and Wan, G. 2006. Impacts of Growth and Inequality on Rural Poverty in China. No 094,
WIDER Working Paper Series, World Institute for Development Economic Research (UNUWIDER).

Zizzamia, R., Schotte, S., Leibbrandt, M., and Ranchhod V. 2015. Vulnerability and the middle class in South Africa. Saldru Working Article 188 NIDS Discussion Article 2016/15. University of Cape 